Keywords:

Home, participatory architecture, house, architecture and human, social responsibility

Article Information

Received:

22 October 2018

Accepted:

22 June 2019

Available online:

13 July 2019

* Lefke Avrupa Üniversitesi Mimarlık Fakültesi Mimarlık Bölümü Lefke, Kuzey Kıbrıs TR-10 Mersin, Türkiye

laras@eul.edu.tr

\section{Touching Human Life in an Architectural Way: Social Responsibility and Home}

Lerzan ARAS*

\begin{abstract}
Touching to human's life and creating a difference was always one of the main priorities of architecture. Especially when it comes to 'home', the responsibility of architect becomes a current issue; not only as a designer but in a social context as well. Starting after the end of the 2nd WW, the theme 'home' was discussed under many economic conditions. Designs for low-income people and spaces under the leading drive of participatory designs invited the architects to remember their social responsibilities. The aim of this study is to address different perspectives of how architects see 'home' since 1945, and evaluate. This outlook takes its roots not from architectural movements but from terms 'being happy and belonging to' in challenging and hard times. For this reason, in the title it is named as 'home' and not house as stated in architectural circles. The examples are chosen from different geographies, years and conditions. The experiences during their life time, the evaluation of the architect's decisions and the relationship between home and individual on social responsibility are the main starting points of this article.
\end{abstract}


Anahtar Kelimeler:

Ev, katılımcı mimarlık, konut, mimar ve insan, sosyal sorumluluk

Makale Bilgileri

Alındı:

22 Ekim 2018

Kabul edildi:

22 Haziran 2019

Çevrimiçi erişilebilir:

13 Temmuz 2019
* Lefke Avrupa Üniversitesi Mimarlık Fakültesi Mimarlık Bölümü Lefke, Kuzey Kıbrıs TR-10 Mersin, Türkiye

laras@eul.edu.tr
Insan Yaşamına Mimarca Dokunmak: Sosyal Sorumluluk ve 'Ev'

Lerzan ARAS*

Öz

İnsan yaşamına dokunmak ve bir farklılık yaratmak mimarlığın her zaman temel önceliklerinden biri olmuştur. Özellikle söz konusu 'ev' olunca mimarın sadece tasarımcı olarak değil, sosyal bağlamda da sorumluluğu gündeme gelmektedir. 2 . Dünya savaşından bu yana 'ev' konusu çok farklı ekonomik şartlar altında tartışılmıştır. Düşük gelirliler için yapılan tasarımlar ve katılımc mimarlığın öncülüğünde oluşturulan yaşam alanları, mimarları sosyal sorumluluklarını hatırlamaya davet etmiştir. Bu çalışmanın amacı 1945'ten bu yana mimarların 'ev'e bakışı konusunda farklı perspektifleri ele almak ve değerlendirmektir. Bu bakış temelini tasarım hareketlerinden değil insan yaşamının zorlandığı anlarda ortaya çıkan, 'mutlu ve ait olmak' kavramlarından almaktadır. Bu nedenle de başlıkta adı mimarca bir terminolojiden uzak olarak konut değil 'ev' şeklinde konmuştur. Örnekler farklı coğrafyalardan, farklı yıllardan ve farklı şartlardan seçilmiştir. Örneklerin kendi var oluş sürelerinde yaşananları ve mimarın karar ve sosyal sorumluluğu bağlamında ev ile birey arasında kurulan ilişkiyi tekrar gündeme getirmek bu çalışmanın temel çıkış noktasıdır. 


\section{Giriş}

Mimarlık yüzyıllardır farklı tanımlarla hayatımızda yer alırken, son dönemlerde mesleğin geleceği ve kullanıcı ile ilişkisi konusunun daha çok tartışılmaya başlandığı görülüyor. Dünyanın geldiği noktada doğal afetler, savaşlar, kirlenme, hızlı nüfus artışı ve benzeri sorunlar daha belirgin olmaya başladıkça, her disiplinin kendini çözüm üreten bir çerçeveye yerleştirme ihtiyacı mimarlık için de çok gerekli bir hal alıyor ve bu bağlamda mimarlık Dutton ve Mann'in ifadeleri ile gücün, kültürün ve sahnelemenin kesişiminde, kimliklerimizin ve farklılıklarımızın oluşumunda önemli bir yer tutuyor (Dutton \& Mann, 1995).

Böylece, değerlendirilmesi gereken başka noktalar olduğu gerçeği de kendini iyice belli etmeye başlıyor: Mimarlık insana yaşamına daha fazla dokunmalı... Mimarlık pratiğinde mimarın sorumluluğu çoğunlukla mesleğe ve kullanıcının isteklerine olan saygı ve farkındalık olarak kendini gösterirken, gereksinimlerin çok yönlü hale gelmesi ve düzenlerin sıklıkla daha zor ekonomik şartlarda kurulması mimarı insanların yaşamlarında daha aktif bir rol oynamaya yöneltiyor. Bu aktif rol mimarinin pek çok düzleminde kendine yer bulabilmekle birlikte, hepimiz için ortak nokta olan barınma yani 'ev' konusu ön plana çıkıyor.

Bu bağlamda 'ev' ihtiyacının mevcut ekonomik şartlarda yeniden tanımlanması gerektiğinde ise aslında mimarlar hafızalarını yenilemek zorunda kalıyorlar; çünkü modern dönemin bitişinden bu yana mimarlığın, gitgide 'daha iyi ve güzelini nasıl yapabilirim?' sorusu ekseninde dönen bir kurgusu olduğu görülüyor. Mimarlık; var olma çabasının da bir sonucu olarak, gün geçtikçe farklılaşan ve karmaşıklaşan bir sistemde kendini temsil etmeye çalışıyor; ancak, her zaman hatırlanması gereken en temel gerçek insanların ' $e v$ ' sahibi olabilmek için 'güzel ve daha farklı' kavramlarının dışında özelliklere de gereksinim duydukları oluyor.

Bu gerçeğin farkına varılması mimarlar için ciddi bir sorunsalı da beraberinde getiriyor. Bunca zaman kendini toplumsal ve yapısal çevre yaratma bağlamında 'özel ve farklı' bir pozisyona oturtan mimarın yeni bir bakış açısı oluşturması gerekiyor ve bu kolay aşılabilir bir eşik olmuyor. Bülent Tanju'nun vurguladığı gibi, “kuşkusuz mimarlık ortamının büyük bir kısmı, eşiği gördüğü an oradan eski güvenli pozisyonuna geri dönmek isteyecektir" (Tanju, 2003).

Bu eşik, modern hareketin son dönemlerinde 2. Dünya savaşının bitiminde Avrupa'da geçilmiştir. Yeniden yapılanma sadece savaşı sıcak yaşayan ülkelerde olmamıştır. Tüm dünya, yaşamı sürdürmenin olmazsa olmazı konut üzerine kendi ekonomik olanakları içinde çalışmıştır. Elbette bu çabaların bir kısmı gecekondular, yanlış kentleşmeler ve kırsal ile kentsel arasında yanlış çözülmeler olarak olumsuz sonuçlar da vermiştir; ancak, iyi örnekler çoktur. Özellikle ekonomik 
olarak düşük gelire fazlaca sahip nüfusun yerleştiği ülkelerde bu eşikte belli mimarların çabaları ve devletin sağladığı olanaklar ile çok olumlu geçişler sağlanmıştır.

Mimar olarak üstünde en çok çalışılan konulardan biri konuttur; ancak, konu zor ekonomik şartlar altında tasarlamak noktasına geldiğinde, mimarın kendi duygusunu, sorumluluk anlayışı ile birleştirerek insanlara 'evim' ya da 'yuvam' diyebileceği bir tasarım sunması gerekir. Amaç artık mükemmel bir mimari örnek olmanın çok ötesinde, insanın yaşamına doğru dokunmaktır. Bu nedenle bu çalışmada mimarca bir terminoloji çerçevesinde kullanılan 'konut' sözcüğü yerine 'ev' sözcüğü tercih edilmiştir. Özellikle de ev kavramının psikolojik anlamını ve ait olma özelliğini ön plana çıkartmak hedeflenmiştir.

Çalışma bu bağlamda 2. Dünya savaşının ağır bilançosunun ardından ayakta kalmaya çalışan insanların yaşamına değen mimari örneklerle başlamıştır. Daha sonra günümüze kadar farklı şartlar, yıllar ve coğrafyalardan örnekler seçilmiş ve bu örneklerin günümüzdeki mevcut durumları değerlendirilmiştir.

\section{Dünya Savaşından Günümüze ‘Ev’e Dokunuşlar}

Dünya 20. yüzyılda 2 büyük savaş gördü. Kayıplar ve yok olan yaşamlar ile birlikte evlerini kaybeden milyonlarca insan çok farklı düzenlere geçti. Savaşın acı ve hüznünün yanında geleceğe bakmak ve yaşama tutunmak için çoğu insanın elinde tek kalan umut ise minimum şartlarda da olsa kendini güvende hissedeceği evlere sahip olmaktı. Bu noktada hem devlet hem de mimarlar için yeni arayışlarla farklı çözümler üretme zamanı gelmişti. 2. Dünya savaşının hemen sonrasında 1946 yılında Almanya'da dönemin mimarlarından Otto Bartning mimari duruşlarını şöyle sergiliyordu: "Bombalar sadece lüks cephelerimizi ve mimari süslerimizi değil binalarımızın temellerini de yok etti. Hiç şüphesiz hepsini tekrar inşa edeceğiz, yeniden var edeceğiz; ama eski cepheleri ile değil; basit, ekonomik, amaca uygun ve işlevsel olacaklar" (Betts, 2003).

2. Dünya savaşı sonrası insanlara yeni konut üretme çabaları 20. yüzyılın en geniş kapsamlı sosyal sorumluluğu olmuştur. Bu, mimarlığın insan ile kurduğu en yakın ilişkilerden ve en zorlu sınavlardan biri olarak da görülebilir; çünkü 'ev' insan için özeldir. Kendini ifade ettiği, yaşamındaki tüm anıları biriktirdiği, kendini yansıttığı yer olarak aynı oranda özel bir ilgiyi hak eder. Elbette 2. Dünya savaşının sonunda evlerin ekonomik olanaksızlıklar içinde oluşturulmaya çalışımasının değeri de buradan gelmektedir: Hiç bir şeyi kalmamış insanlara yeni anılar oluşturabilecekleri ve acılarını unutabilecekleri yaşam alanları yaratmak ve bunu zor’u başararak yapmak... 
Bu dönemin en başarılı ev örneklerden biri İngiltere'de görülmüştür. İngiltere üretimi hızlı, maliyeti düşük prefabrikasyon evlerin insanlar için ilk anda ciddi bir cankurtaran olduğunu düşünerek hızla üretmeye başlamış; savaş bitiminden 10 yıl sonra ülkede yaklaşık 450.000 ev inşa edilmiş (Şekil 1) ve bunların merkezi planlı yerleşimleri ile komşuluk ilişkileri de sağlanmıştır (Turner, 2015). 2 yatak odalı bu müstakil konutlarda açık bir mutfak ve yine prefabrike şekilde oluşturulmuş bir banyo yer almıştır. Dönemin şartlarına göre oldukça iyi sayılabilecek bu evlerin kendilerine ait küçük bahçeleri ve sundurmaları da tasarlanmıştır. Günümüz şartlarına göre zayıf da olsa, içeride var olan tuvalet ve küçük mutfak insanların yaşam şartlarını belli oranda kolaylaştırmıştır. Kimlerin bu prefabrike evlerde yaşayacağı konusuna devlet karar vermiş, özel durumda olan ya da çocuklu ailelere öncelik tanınmıştır. Bu yapıların kısa süreli barınma ihtiyacına cevap vermek için yapıldığı bir gerçektir; ancak, 2011 yılına gelindiğinde hala ayakta kalan ve oturulan 187 tane ev mevcuttur (Prefabs, n.d). İngiliz hükümetinin evleri tahliye etme ve bir kaçı hariç hepsinin yıkılması konusuna onay vermesine kadar geçen süreçte insanlar burada kendilerine gerçek bir 'yuva' kurmuşlardır.

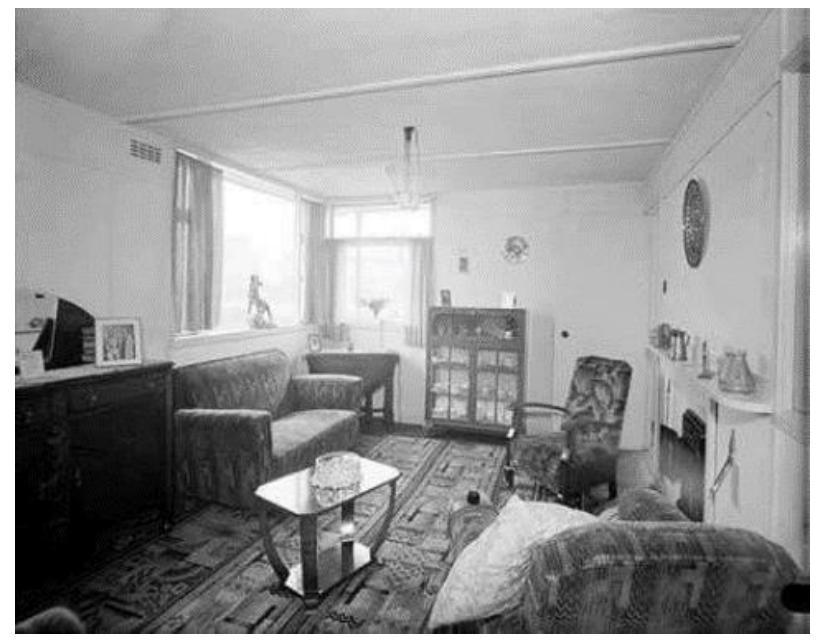

Şekil 11947 yılında Hopewell Road, Kingston'da inşa edilmiş bir savaş sonrası prefabrike evin iç mekânı (Prefabs, n.d.).

Savaş sonrası çok zarar görmüş Avrupa kentlerinden biri olan Berlin'in yeniden inşa edilmesi de kolay olmamıştır. İnsanlar kendi olanakları ile evler yapmıştır. 1944 yılında Berlin'in güneyinde Lichterfelde bölgesinde yapılan evler buna güzel bir örnektir. (Şekil 2) Çok basit bir planla yapılan bu evlerin sadece 2 küçük yaşama alanı ve bir deposu vardır. Islak hacimler evin içine dâhil edilmemiştir. 1954'e gelindiğinde Batı Berlin'in üçte birinin 21.000 ailenin yerleştiği, plansız ama insanların kendi kendilerine inşa ettiği evlerden oluştuğu görülmektedir (Florian, 2013). Her ne 
kadar savaş bitiminde alternatifler zaten çok kısıtlı da olsa, bireysel çabalarla oluşan düzenlerin insanları güvende tuttuğu bir gerçektir.

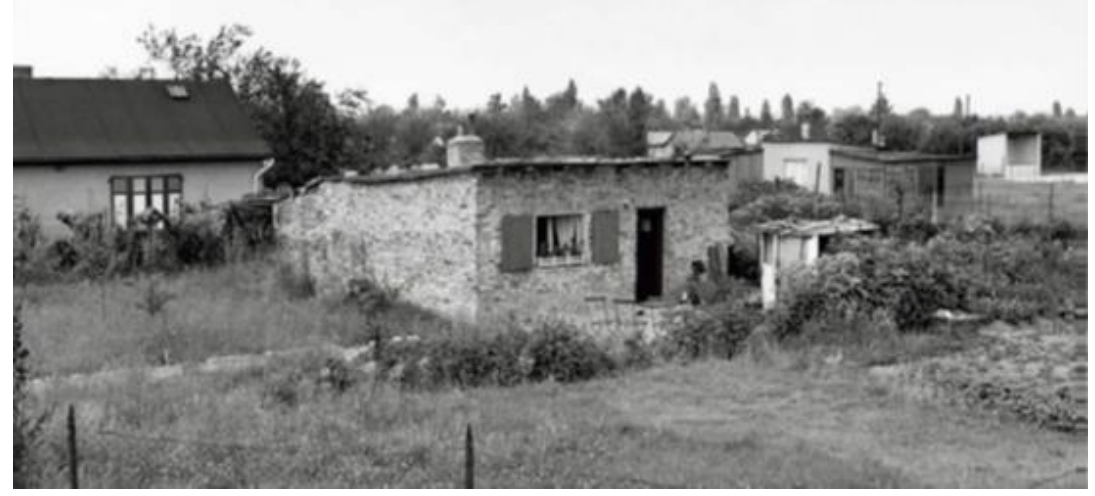

Şekil 21955 yılında Berlin'de Märkisches Viertel bölgesinde yapılmış "yeşil gecekondular" (Florian, 2013).

Mimarlar savaş sonrası kentleri yeniden inşa ederken, evrensel olarak kabul edilebilecek ilkelerle hareket etmişlerdir. Bu hareketlerin içinde en dikkat çeken ve etkisini gösteren ise CIAM'dır. İsviçre'de 1928 yılında kurulan ve 1956 yılına kadar toplantılarını sürdüren CIAM; felsefesini 'mimarlığın çağdaş programını formüle etmek, modern mimarlığın genel fikirlerini savunmak, bu fikirleri teknik, ekonomik ve sosyal çevrelere duyurmak ve mimarlık problemlerinin çözümlerini görmek' olarak ortaya koyan bir yapılanmadır (Mumford, 2000). Le Corbusier ise bu çerçeveye bağlı olarak mimarlığı "Mimarlık bir ahlaklııı meselesidir" şeklinde tanımlamaktadır (Le Corbusier, 1986). Bu idealizm onun tasarımlarına kusursuz geometriler olarak yansırken, konunun ekonomik ve sosyal yönü aynı oranda yer bulmamaktadır. Nitekim CIAM'da belirlenen 'oturma, çalışma, eğlenme ve ulaşım' fonksiyonları dönemin karmaşık kent yapısına kesin çözüm getiremediği gibi modern mimarlığın ölümü olarak adlandırılabilecek yapıların oluşumunu da engelleyememiş ve dönem içinde mimarın ev'e dokunuşunun ekonomik zorluklar ve yanlış hesaplanan gelecek öngörüleri ile başarısız olduğu örnekler de oluşmuştur. Bu örnekler içinde en çok konuşulan ise New Orleans'ta 1954 yılında inşa edilen ve 1972 yılında dinamitlenerek yıkılan Pruitt-lgoe konutlarıdır (Jencks, 1977). (Şekil 3) Minoru Yamasaki'nin tasarımının ekonomik nedenlerle çok değişerek uygulanmış olmasının yarattığı niteliksiz ortak mekânlar bu yapıyı kısa sürede ev olma özelliğinden uzaklaştırmıştır. 57 dönüm üzerine kurulu ve her biri 11 katlı 33 binanın (Comerio, 1981) yıkımının 'modern mimarlığın ölümü' olarak adlandırılması konusu çok yazıya konu olurken, asında çok başka derslerin de çıkarılması gerekmektedir. Mimar ideal prensiplerle ve uygun 
şartlarla tasarım yapsa da, ekonomik gücün ve sosyal şartların hesaplarının da doğru olması gerekmektedir.

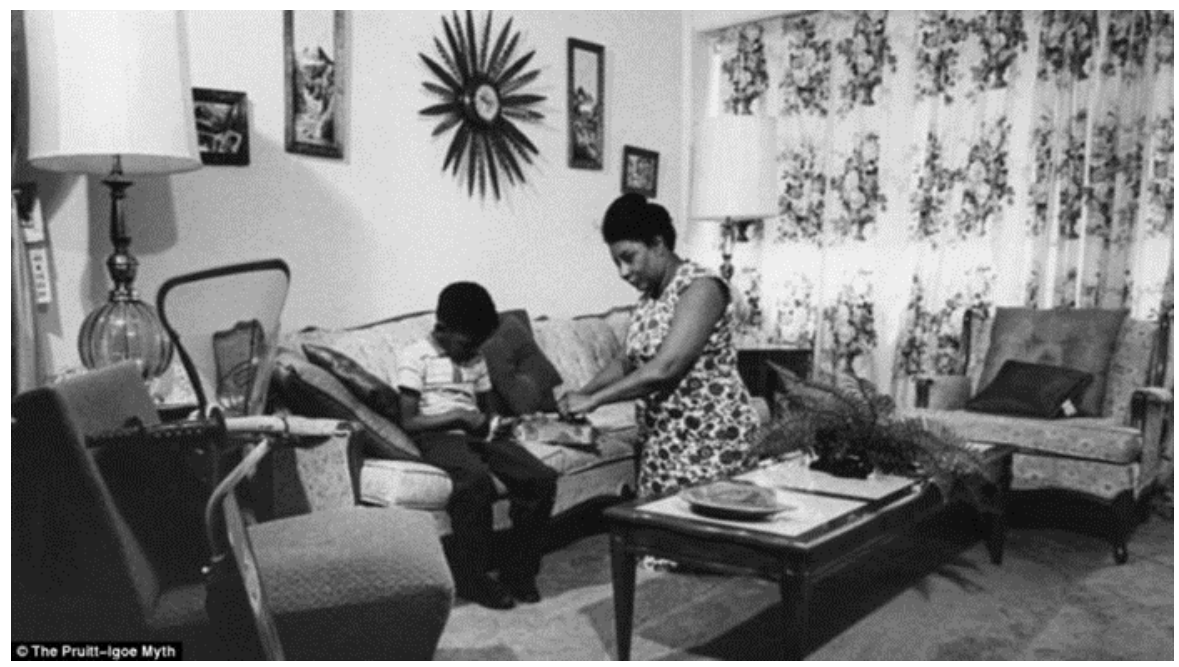

Şekil 3 Pruitt- Igoe'da bir 'ev' ve birlikte ders çalışan anne- çocuk (Pruitt- Igoe, 2016).

2. Dünya savaşının bitiminin ardından devletin yerel yönetimlere düşük gelirliler için finansal destek olma çabası, konut ihtiyacının savaştan dönen askerlerle birlikte çok artması ile başarıya ulaşamamıştır. 13.000 dar gelirlinin (Comerio, 1981) yeterli havalandırması ve doğal iklimlendirmesi olmayan, ortak alanlardan yoksun ve güvensiz alanlarda yaşamak durumunda olmasının en büyük nedeni de budur. Ne Le Corbusier'nin idealizmi, ne de CIAM'ın alternatifleri ekonomik gücün olmadığı noktada mimarı iyi bir çözüm noktasına getirememiştir.

Aslında farklı sosyal statüler ve farklı kültürlerden insanların aynı mekânları paylaşması ve tasarımda söz sahibi olamamaları da bu sonu hazırlayan etkilerdendir. Insanların ekonomik güçlük içinde de olsa onları mutlu edecek, evini istediği gibi yapacak ortamlara ihtiyacı vardır. Bu konuda özellikle kullanıcıyı tasarım sürecine katmak ve ona arzu ettiği yaşam biçimini sunmak konusunda yeni görüşler oluşurken, 60’lı yılların sonu ve 70'li yıllar mimarlık disiplininde sınırların bulanıklaştığı yılları temsil eder. Modernizmin avangard ve elit düzeninden daha tüketim odaklı ve gündelik bir düzene geçiş gözlemlenirken, bir yandan Venturi'nin Las Vegas tanımlamaları doğrultusunda ışıltılı bir mimarlığın örnekleri de belirgin olmaya başlamaktadır. Sosyal sorumluluk konusuna daha çok eğilen tasarımcılar da aynı bağlamda gündeme gelmektedir. 70'li yıllar modern dönemin rasyonel bakışının değişmeye başladığı yılları temsil ederken, dünya ekonomik olarak da bu değişimi yaşamaktadır. Pruitt-ıgoe'nun yıkılması mimarlığı bir anlamda daha gerçekçi ve daha gündelik yaşamın içinde olmaya davet etmektedir. Sonuçta 1973'de kendini iyice belli eden petrol krizi (Aras, 2013) ve dünyayı daha eşit bir hale getirme çabaları mimarları yeni bir 
sorumluluk içine çekmektedir: İnsanların istediği yaşamı sürebilme özgürlüğünü kendi ekonomik çerçeveleri içinde düzenlemek fikri...

Hassan Fathy, aynı yıl basılan 'yoksullar için mimarlık' (architecture for the poor) adlı kitabının giriş bölümünde gençlik yıllarında ona sorulan bir soruyu dile getirir: Size bir milyon pound verilse ne yapardınız? Fathy'nin buna cevabı şöyledir: “iki olası cevabım vardı; bir yat alıp arkadaşlarımla Bach dinlemek, ya da fellahların benim istediğim gibi bir hayat sürmelerini sağlamak" (Fathy, 1973). Aslında batı kökenli bir eğitim alan Mısırlı mimarın, modernizmin Mısır'daki başarısızlığını gördükten sonra, modern mimarlığın kuralları yerine kerpiç malzemeli, tonozlu ve geleneksel yöntemlere dayalı gölgeleme ve havalandırma tekniklerine döndüğü bilinmektedir. Bunun sonucunda ise kendi ifadesi ile daha mutlu bir toplum oluşmuştur (Mallgrave \& Goodman, 2011).

Mutlu olma ve ait olma kavramlarının bir ev için ne kadar önemli olduğu gerçeği ve bireylerin tasarım sürecine dâhil olma isteği mimarlık çevrelerinde kabul edilirken, örnekler artar. Yine 1973 yılında John Turner ve Robert Fichter'in editörlüğünü yaptıkları 'inşa etme özgürlüğü' (freedom to build) adlı kitap yayımlanır. İnsanların isteklerini ve gereksinimlerini gözönüne aldığınızda standart altı olan ile gerçekten içinde yaşamaya uygun olanın arasındaki farkın netleşmesi ve bireylerin kendi evlerini kendi bütçeleri dâhilinde inşa edebilir olması düşüncesi, bazı mimarları ve sosyal farkındalık konusunda çalışan kurumları Avrupa'nın pek çok yerinde düşünmeye sevk eder (Turner \& Fichter, 1973). Turner'in 1957- 1965 yılları arasında Peru'da gecekondu bölgelerini islah etmek için yaptığı çalışmalarda ortaya koyduğu, 'kullanıcının evini kendi inşa etmesinin ötesinde finansal açıdan idare etmesinin' doğru olduğu görüşü günümüzde de geçerlililiği korumaktadır.

70'li yıllarda sosyal sorumluluk bağlamında tasarıma kullanıcıyı katma ve mimarın rolünü değerlendirme konuları fikri Belçikalı Mimar Lucien Kroll, Hollandalı mimar John Habraken ve Macar-Fransız mimar Yona Friedman önderliğinde tartışımaktadır. John Habraken, 2011 yılında Teerds ve ve Havik'le yaptığı sohbette mimarın değişen rolünü şöyle ifade etmektedir:

Ben, mimarı kat planı tasarlamak konusunda özgürleştirdim. Bir kent planlamacısı mimariyi değil, mimarinin içinde çalışacağı çerçeveyi kurgular. Bu da bize farklı seviyelerle çalışma fikrini verir. Bir tasarımcı olarak son noktayı görmeniz gerekmez; ama önemli olan noktaları harekete geçirmeniz beklenir. O yüzden artık mimarın kendini dışa vurumu ve orjinalliği konularından bağımsız olarak, herkesin ortak kullanımda serbestleşebildiği ve kendi kimliğini ortaya koyabildiği sistemlerden bahsetmeliyiz (Teerds et al, 2011).

Lucien Kroll da benzer bir çerçevede çalışmalarını sürdürür. 1961-1969 yılları arasında Rwanda'da konut ve kentsel tasarım komisyonlarında uzun süre görev alan mimar yerel yaşam ve buna bağlı yapım teknikleri ile yakından ilgilenir (Spatialagency, n.d). Bunu takiben 1972 yılında Brüksel'de 
Louvain Üniversitesi’nde yaptığı Tıp Öğrencileri Yurdu projesi ‘La MéMé' katılımcı mimarlığın en dikkat çeken örneklerinden biri olur. (Şekil 4, 5) Kroll'un deyimiyle 'çoğalan mimarlık' (incremental architecture), kullanıcıya kendi yaşam alanını kendisinin üretmesi şansını veren, yapının evrimine ve mekânların kişiselleştirilmesine izin veren bir strateji olarak bu projelerde karşımıza çıkar (Erten, 2015).
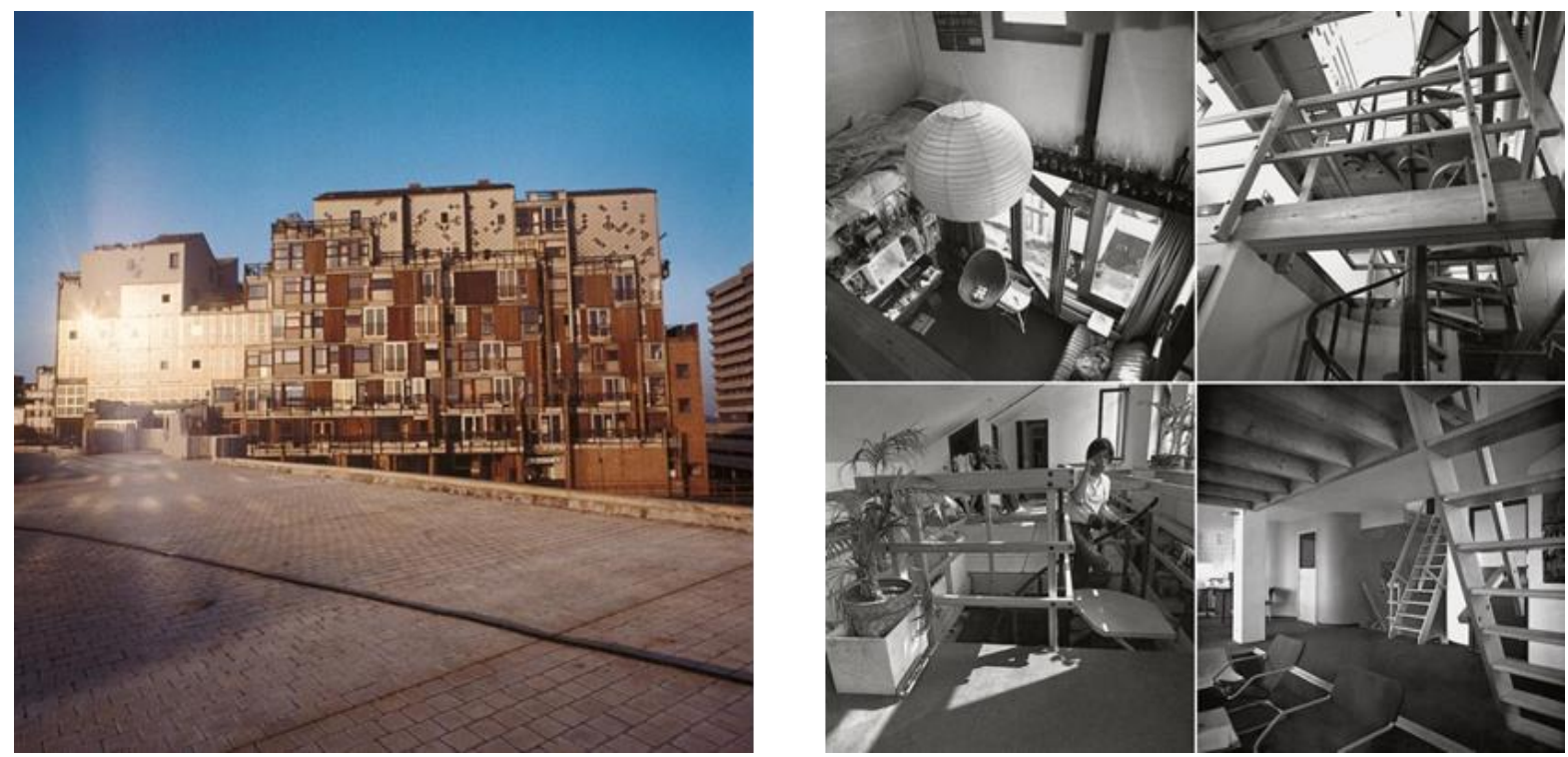

Şekil 4-5 La MéMé ve kullanıcı öğrenciler (Lucien Kroll, n.d.).

Aynı yıl içinde mimarın sosyal sorumluluğunun başka bir ifadesi olarak İngiltere'de doğu Londra'nın yoksul mahallelerinden biri olarak kabul edilen Poplar'da modern ve brutalist mimarinin bir örneği görülür. 1972 yılında Alison and Peter Smithson tarafından tasarlanan geç savaş sonrası sosyal konut yerleşkesi olan Robin Hood Gardens sosyal değerlere verilen önemi gösterme açısından güzel bir örnek olarak karşımıza çıkar. Kullanıcının ortak alan kullanımları ile birlikte komşuluk ilişkilerinin gelişmesi, bu tasarımın önemli kıstaslarından biridir. Yapının mimarları 'gökyüzündeki sokaklar' adını verdikleri her 3 katta bir yaratılan büyük gezinti balkonları ile (Robin Hood Gardens, n.d.). insanların sosyalleşerek ev yaşantısının hem içeride hem dışarıda oluşmasını hedefler. (Şekil 6, 7) 

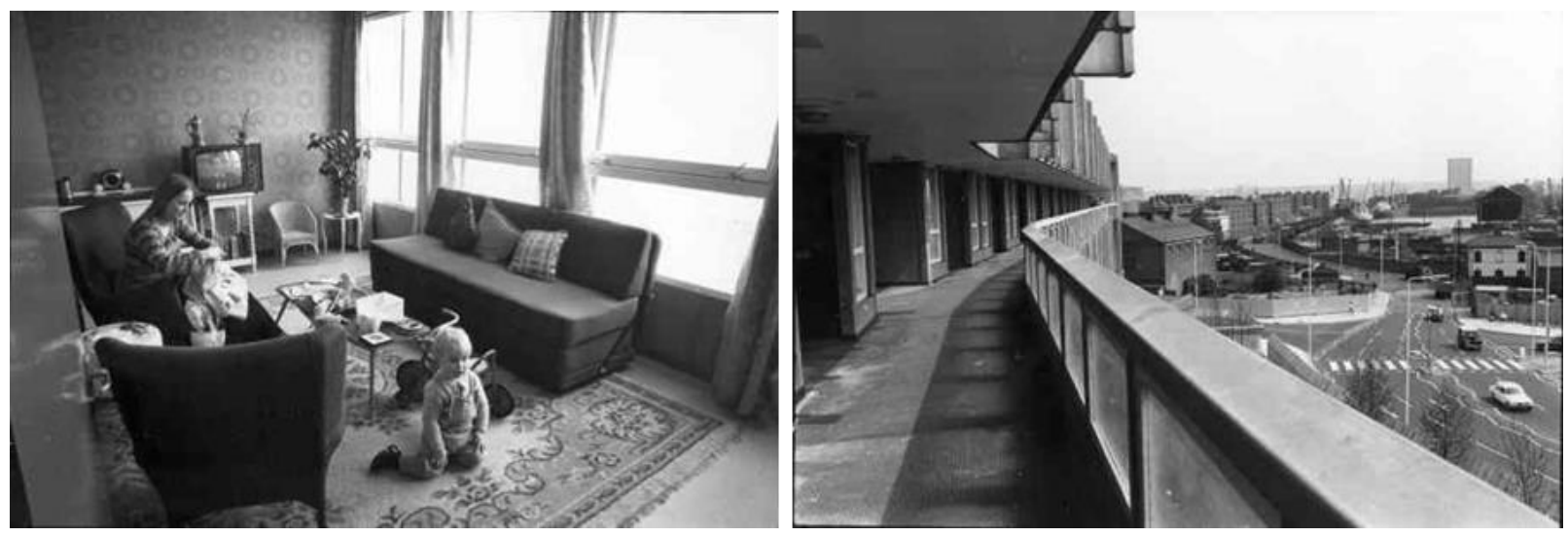

Şekil 6-7 Robin Hood Gardens iç mekânı ve 'gökyüzü sokakları' (Poplar, n.d.).

Ancak, bu girişim çok başarılı olmaz. Dar sokakların insanları cezbeden bir yönü oluşamayınca yıllar içinde insanların ev kavramına uymayan bir düzen baş gösterir. Robin Hood Gardens evlerinde oturanların çoğu ait olma ve güven duyma kavramlarının eksikliğini hisseder. Rattenbury'nin anlatımıyla, bu evler şehir planlamanın modernist ilkelerine öyle derinden bağı tasarlanmıştır ki, insanların içinde yaşadıkları 'şeylerin' ev gibi çalışmasına ya da görünmesine olanak yoktur (Rattenbury, 2011).

Böylece yapının kaderi Pruitt-Igoe gibi olur ve Ağustos 2017'de yıkımına başlanır. Tasarımcıların mimar oğlu Simon Smithson'un Vandalizm olarak tanımladığı bu yıkımın oluşmaması için pek çok mimar çalışır. Bu çabalar boşa çıkmakla birlikte, yine de hatıralardan tamamen yok olmasına da razı gelemeyenler olur. Sonunda Victoria \& Albert Müzesi (V\&A), yapının 3 katlı 9 metre yükseklikte 5.5 metre genişliğinde bir kısmını korumaya aldığını ve Venedik Bienalinde sergileneceğini duyurur (Aras, 2018).

Günümüzde mimarlar teknolojinin tüm yeniliklerini takip etme şansına sahip. Ancak, konu insan yaşamı, onun ihtiyaçları ve beklentileri ve özellikle de yaşamımızın en önemli parçası olan ev olunca, tek başına teknolojinin fayda sağlamayacağı ortamlar oluşabiliyor. Yıllardır pek çok mimar insanın ev ile olan ilişkisini çözmeye çalışıyor. Le Corbusier'nin “ev, içinde yaşanılacak makinedir..." özdeyişi çok mekanik bir ifade gibi görünse de, aslında konunun can alıcı noktasını işaret eder: Ev, bizi barındırmanın ötesinde, bizim için kusursuz olmalı, mutlu etmeli, gündelik yaşamımızı kolaylaştırmalı ve hatıraları barındırabilmelidir. Kişi kendini o 'ev'e ait hissedebilmelidir. 1920'li yıllarda Le Corbusier tarafından Bordeaux yakınlarında Pessac'ta şeker fabrikası işçileri için tasarlanan konutların günümüzde de kullanılır olma sebebi budur: Kullanıcının yaşam alanlarını dönüştürme şansına sahip olmaları ve evlerinde kendilerini mutlu hissetmeleri... 1981 yılında bu evleri ziyaret eden gazeteci Huxtable bu konutları şöyle anlatır: 
Kullanıcıların yaptığı değişimler orijinal ana fikri bozmamış, tam tersi güçlendirmiş; kendi istediklerini yapmalarına olanak tanıdığı gibi, bu gereksinimlerin aslında neler olduğunu anlamalarını da sağlamış. Le Corbusier'nin 5 temel ilkesini elbette görebiliyorsunuz. Herkes onun 'konut içinde yaşanılacak bir makine'dir' deyişini hatırlar. Ancak, genelin unuttuğu onun bir sonraki cümlede söylediğidir:

İnsanın bir kalbi vardır ve evinde mutlu yaşayabilmesini sağlamak bizim görevimizdir. (Huxtable, 1981)

Ev'e mimarca okunmak tabii ki sadece düşük gelirliler için üretmek demek değildir; ancak, günümüz dinamiklerinde yaşamın ağırlığını hafifletecek çözümler önem kazanmaktadır. Mimarın kendi prensipleri ve sosyal yaşam değerlendirmesi çerçevesinde kullanıcıyı tasarıma katması, mimar-kullanıcı ilişkisini daha özel kılmakta ve olumlu çözümleri arttırmaktadır.

Yakın dönemde katılımcı mimarlık izlerini takip eden mimarlar içinde Şili'li mimar Alejandro Aravena sayılabilir. Mimarın düşük gelirliler için tasarladığı konutlar mimarın sorumluluğu konusunu yeniden tartışma ortamlarına yerleştirir. 2003 yılında Aravena ve mimarlık şirketi Elemental Şili Quinta Monroy bölgesinde 93 aile için bir konut çözümü üretmek üzere bölgenin yönetimi tarafından davet edilirler. 'Borçsuz dinamik sosyal konut' (Vivienda social dinámica sin deuda) olarak bilinen bu yeni ve yaratıcı uygulamayı yürürlüğe koyan yerel yönetim, her ailenin 7.500 dolar değerinde tek bir çek alarak bununla önce arazi ve çevre bedelini sonra bir konutun fiziksel yapısını karşılamasını hedefler (Ballesteros, 2010). Bu teşvik aslında yetersiz gibi dursa da, Aravena bir çözüm önerir: Kalitesiz ama tam bitmiş evler yerine yarım bitmiş ama kaliteli evler sunmak...

$\mathrm{Bu}$; bir anlamda kullanıcı tarafından yapılması mümkün olmayan kısımların mimar tarafından çözülmesini, geri kalanının ise belli kurallar çerçevesinde kullanıcının kendi kontroluna verilmesini hedefleyen bir sistemdir. Bu sistem doğrultusunda tasarım yapan Aravena dar gelirli pek çok insanın kendisine ait bir eve kavuşmasını sağlar. (Şekil 8, 9) 2013 yılında Archidea dergisine verdiği röportajda Aravena mimari değerlerin değişmesinin gereğinden bahseder. Mimarlık yapısal çevrenin karmaşıklığını ve formların stratejik kullanımını sentezleyecek bir bütüne erişmelidir (Aravena, 2013). 

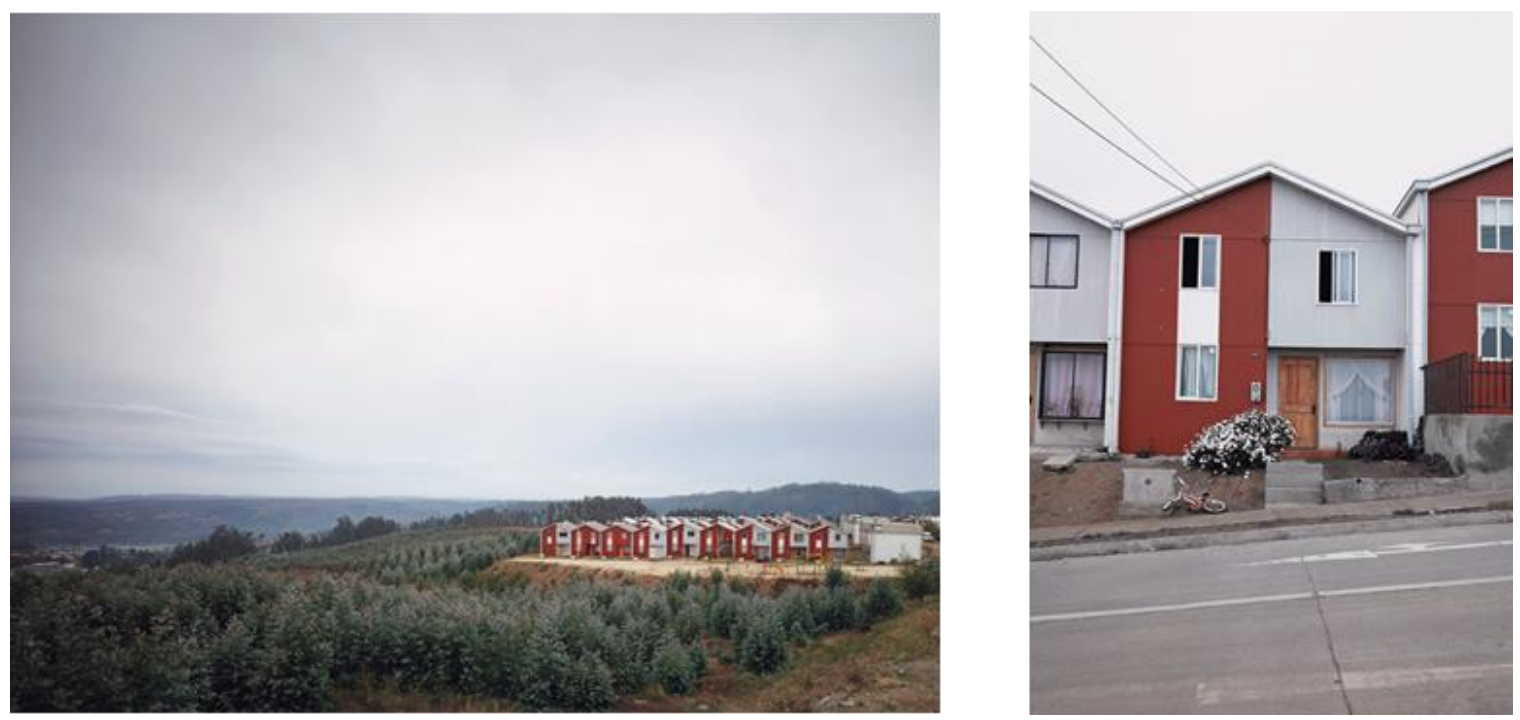

Şekil 8-9 Villa Verde Evleri (Alejandro Aravena, 2016).

Öte yandan Aravena'nın bu cesur yaklaşımını farklı yorumlayanlar da olur. Boano ve Perucich, Aravena'nın çalışmalarının insanların iyi bir mimarlığa kavuşmasını sağlamadığını ve yıldız mimarlar için sosyalleşme sağlamak için bir yol olduğunu iddia ederler (Boana \& Perucich, 2016). Bu iddialara rağmen Aravena'nın öncülük ettiği sosyal farkındalık ve insan yaşamına mimarca dokunmanın önemi mimarlık dünyasında özel bir yer edinir. Artık dünyanın daha zor bir yaşam alanı olduğu, savaşların çok insanı evsiz bıraktığı ve ekonomik sıkıntıların bir ev sahibi olmayı zorlaştırdığı gerçeği herkes tarafından kabul görmektedir. Bu çerçevede aynı zamanda kültür, sosyal ortamlar, gündelik yaşam ve insan ile olan ilişkiler de tekrar değerlendirilmelidir. Böylece 2016 yılında Pritzker ödülünü alan Aravena'nın tekrar gündeme taşıdığı sosyal sorumluluk yolu daha çok dikkat çekmeye başlar.

2 sene sonra 2018 yılında Pritzker ödülünü Hintli mimar Balkrishna Doshi alır. 70 küsur yılı içeren meslek hayatına Le Corbusier ile çalışmalarını da katan Doshi'nin yerel kültüre inancı ve insan yaşamının gereksinimi olan mekânsal kaliteye saygısı tüm tasarımlarında görülmektedir. Bu tasarımlar içinde ise Aranya konut projesi mimarın sosyal sorumluluk bilincini ortaya koyduğu en önemli eserlerinden biridir. 1989 yılında Indore'de tasarladığı bu toplu konut yerleşimi 86 hektarlık bir yerleşim üzerinde 6500 aileye ev sahipliği yapmaktadır (Aranya, n.d.). Doshi'nin kendi ifadesi ile "sadece ev değil, mutlu bir topluluğun yaşadığı evlerdir ve önemli olan da budur" (Balkrishna Doshi, n.d.). 1996 yılında Ağa Khan mimarlık ödülünü de kazanan bu tasarım, sürdürülebilir bir toplumun günümüz örneklerinden biri olmasının yanı sıra, mimarın insan yaşamına nasıl dokunabileceğinin güzel ifadelerinden biridir. (Şekil 10, 11). 


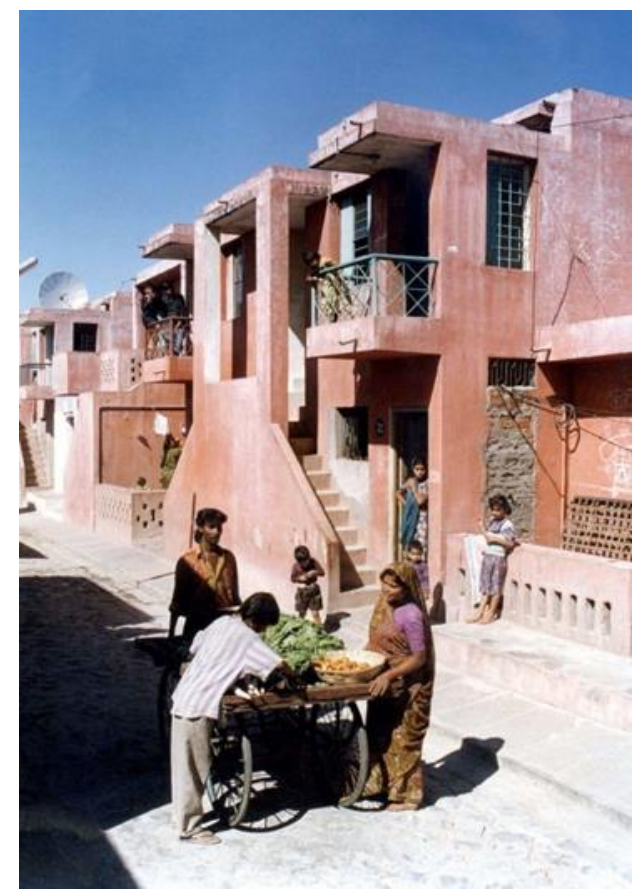

Şekil 10 Aranya evleri (Asia, n.d.)

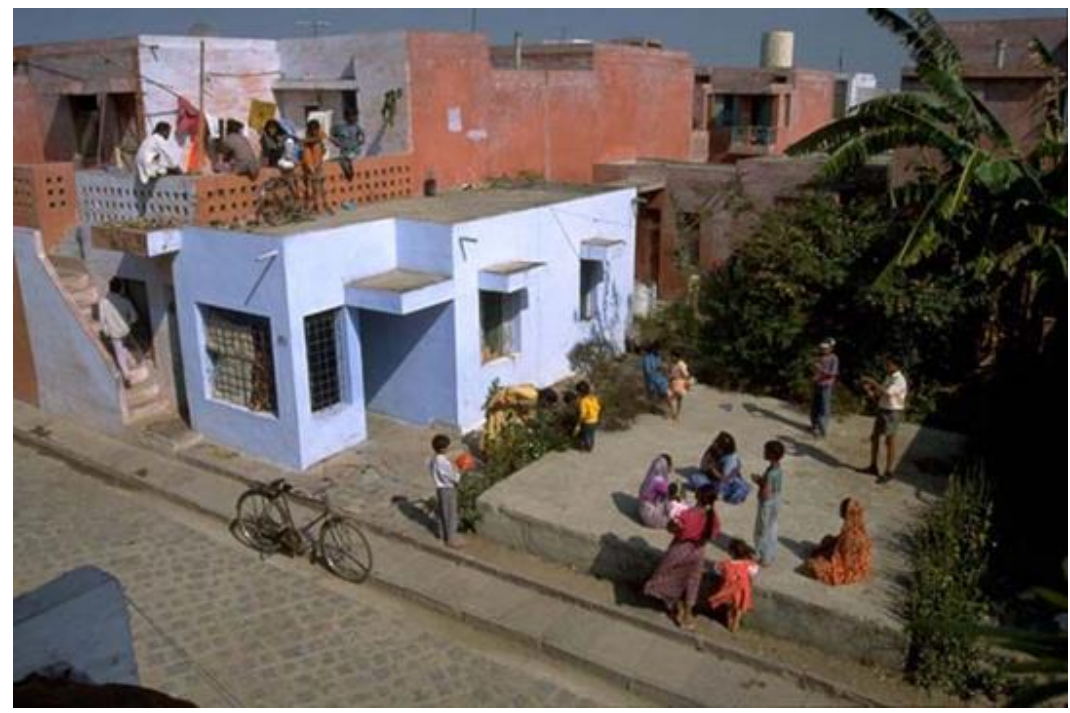

Şekil 11 Aranya evleri (Archnet, n.d.)

Günümüze daha yakın dönemlere göz atıldığında, 2012 yılında farklı bir coğrafyada Vietnamlı mimar Vo Trong Nghia'ın çelik çerçeve profili ile çok düşük maliyetli ve doğa dostu evler tasarladığı görülür. Illk prototip'in arkasından 2013'te de başka örnek evler yapılmaya başlanır. Mimarın amacı 2. Dünya savaşından beri en üst düzeye çıkan zorunlu göç ve doğal felaketler sonucu evini 
kaybeden insanlar için her ortamda kullanılabilecek evler tasarlamaktır. (Şekil 12, 13) Bu evlerin ilk sergilenişi ise 2015 yılında Şikago Mimarlık Bienali'nde olur. Vietnam'ın özellikle tropik iklim koşullarında çok fazla yıpranan ve yıkılan evlerinin yerine konforlu ve dayanıklı bir alternatif çözüm olacağı öngörülen bu tasarımlara S- evler (S houses) adı verilir. Mimar ise amacını şu sözlerle açıklar: “Doğa ile insan arasında bir köprü kurmaya ihtiyacımız var ve sadece zengin olanlarla değil herkesle ilgilenmeliyiz" (Trong Nghia, n.d.).
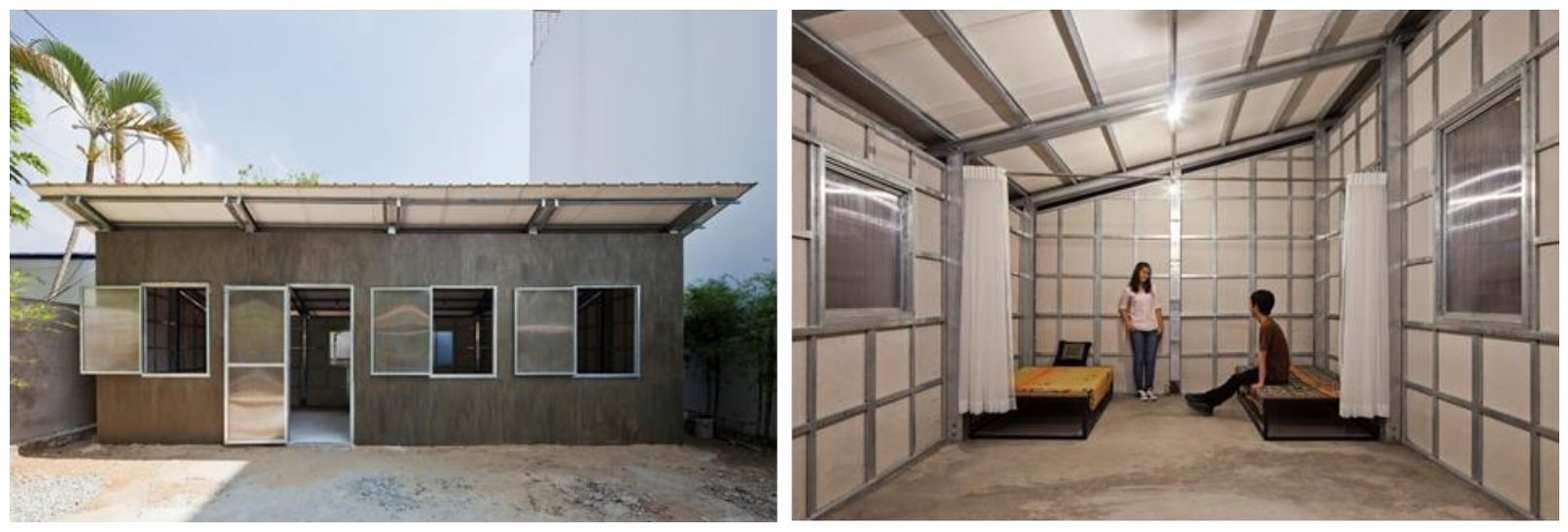

Şekil 12-13 S- Evi tip 3 (Vo Trong-Nghia, n.d.).

Bu çalışma, her ne kadar sosyal farkındalık yaratmak için çok değerli bulunsa da, konu ile ilgili endişeler de vardır. Ulusal Singapur Üniversitesi Mimarlık bölümü öğretim üyelerinden Profesör Chang Jiat Hwee'ye göre; "Nghia çok iyi bir mimardır ve gerçekten firması ile birlikte aileler için bireysel anlamda çok konut tasarlamıştır. Ancak, toplu konut için ilk örnek (prototip) tasarlamak çok başka bir iddia olarak görülmelidir" (S-houses, n.d.).

Bu örnekler 2. Dünya savaşından günümüze çok farklı yılları ve farklı coğrafyaları içermektedir; ancak, kullanıcılarının ekonomik anlamda zorlanması ve yaşam alanları hakkında söz sahibi olma şansını elde etmek istemeleri onları ortak bir paydaya getirmektedir. Bu evler, içlerinde yaşayan insanların kendilerini mutlu ve güvende hissetme duyguları ile değerlendirildiğinde şu soruyu da sormak gerekebilir: Bu yapıların yıllar içinde kaderi ne olmuştur?

Pruitt-Igoe ve Robin Hood Gardens konutları yıkılarak tarihe karıştılar. Pruitt-lgoe, Jencks tarafından bir anlamda 'modern mimarlığın ölüm ikonu' olarak adlandırılarak mimarlık okullarının modern dönem tarih notlarında yerini aldı. Robin Hood Gardens ise bir parçası ile Victoria \& Alberts müzesinin salonlarında yaşamaya devam ediyor.

Ingiltere'de 2. Dünya savaşı sonrası yapılan evler kısa süreli barınma ihtiyacına cevap vermek içindi; ancak, buradan taşınmamayı tercih edenler oldu. Gazeteci Sonia Zhuravlyova 2013 yılında 
bölgede az sayıda kalan evlerin kullanıcılarını ziyarete gittiğinde beklemediği bir manzara ile karşılaştı: İnsanlar bu evlerde mutluydu. Sohbetlerde ortaya çıkan, insanların savaş sonrasında kendilerini yapayalnız bulmalarına rağmen, bu evlerin cephelerinin birbirlerine bakmasının verdiği yakınlığın o yalnızlık duygusunu hiç hissettirmemiş olduğu gerçeğiydi. Aradan geçen yıllar içinde de hala kuş seslerini duyabilmeleri ve kentin gürültüsünden uzak kalabilmiş olabilmeleri ise onlar için ayrıca önem taşımaktaydı (Zhuravlyova, 2013).

Vietnam'da ise mimar 2017 yılında S-evleri'nin sayısını 38'e çıkartmıştır. Ba Vi bölgesinde yapılan bu evler klimasız, saz ve saman çatılı, dörder yataklı ve son derece sadedir. Bölgede inşa edilen evleri gezen bir Budist rahip, dört gözle kalmayı bekledikleri bu evler için şu yorumu yapar: "Bizim için yeterince iyi çünkü bizim basit bir hayatımız var!" (Prefabricated housing, 2017). Şu an bu proje beklendiği kadar hayata geçebilmiş değil; ama mimarın yerel malzeme ve az maliyet ile yaptığı projeler devam ediyor.

Aravena'nın sosyal sorumluluk ve ev kavramlarını tekrar mimarlığın ilgi alanına yerleştirmeyi başardığı ve uzun süre tartışmaların gündeminde kalan sosyal konut tasarımları ise daha talihli bir süreç geçirirler. 2016 yılının Mayıs ayında Michael Kimmelman New York Times'ın bir yazarı olarak bölgede insanları ziyaret ederek 27 yaşındaki Noemi Moran ve 37 yaşındaki Luis Flores'in evlerini ayrı ayrı gezer, onlarla sohbet eder. Moran, annesinden ayrılıp Villa Verde'ye ilk taşındığında yalnızlığından ağladığını ama bir sene içinde biriktirdikleri para ile evlerini tamamladıklarını söyleyerek gururla evini gösterir. Aynı şekilde Luis Flores de önce yarım bir eve sahip olma konusunda endişeli duyduklarını ama sonra bir sene içinde evlerini bitirdiklerini, sıcak sularının aktığını ve 3 çocuklarının da artık kendi odalarına sahip olmasının önemli olduğunu ifade eder. Yani, aile mutlu yaşamaya devam etmektedir (Aravena, 2016).

Balkrishna Doshi'nin 1989 yılında tasarladığı Aranya konutlarında da gündelik yaşam sosyalleşen bir topluluk ile devam etmektedir. Buradaki en büyük etken ise Doshi'nin sosyal yaşamı destekleyen tasarımı ile insanların kendi kendilerine yetebilecek bir mekanizma yaratabilmiş olmasıdır.

Belçika'da ise Lucien Kroll'un öğrencilerle birlikte inşa ettiği yurt binasının çok değişime uğradığı görülmektedir. Çoğunlukla tesisat iyileştirme ve güvenlik adına yapılan bu değişimler yapıyı orjinal halinden oldukça çıkarmıştır. 2016 yılında Reinier de Graaf Architectural Review dergisinde Lucien Kroll ve paylaşımcı mimarlık üzerine bir yazı hazırlar. De Graaf bu yazısında 30 sene sonra Lucien Kroll'u ziyaretini anlatır. 98 yaşındaki mimarın geçmiş günleri çok hatırlamamasına rağmen söylediği bir cümle hepimizin aklına ve yüreğine yerleşmesi gereken bir deyiştir: "Vitruvius'a göre mimarlık 3 temel üzerine kuruluydu: güzellik, kullanışlıık ve dayanıklılık... Ancak insanlığı unutmuştu ve bence bunun değişmesi gerekir" (User participation, n.d.). La MéMé bugün 
değiştirilen iç mekânları ile anıt olarak tescillenmeyi beklemekte ve mimarın insan yaşamına dokunuşunun güzel bir örneği olarak tarihte yerini almaktadır.

\section{Sonuç}

"Başımın üstünde bir dam isterim, bana huzur sağlayacak bir mekân versin" Bu istek Tester ve Wingfield'in 2013 yılında evin anlamını araştırmak için yaptıkları sohbetlerin birinde dile getirilir (Tester \& Wingfield, 2013). Bu, naif ve sade bir dilektir; ancak, akademik bir çerçeveden değerlendirildiğinde, evin insan için anlamının kültürel, fiziksel, sosyolojik ve psikolojik olmak üzere çok boyutlu olduğunu ifade etmektedir.

Judith Sixsmith 'ev' kelimesinin çok farklı disiplinlere ve araştırmacılara göre tarifini yaptığı makalesinde, eve anlam katabilecek 20 ölçüt ortaya koyar. Bu kategorilerin her biri ev için özel bir noktayı işaret ettiği için önemlidir. Hiç biri diğerinin önüne geçmez ve birlikte olmaları anlamın artmasını sağlar. Listenin en başında ise 'mutluluk, ait olma ve sorumluluk' kavramları yer alır (Sixsmith, 1986).

Aynı yıllar Sebba ve Churchman (1986), evin 'eşsizliği' üzerine yaptıkları çalışmalarını yayınlarlar. İsrail'de 185 kişi ile yaptıkları görüşme sonucunda vardıkları nokta ise şu olur: Ev; fonksiyonel bir yapılanma prensibi ön plana alınarak tasarlanmış bile olsa, insanlar kendi özgür iradeleri ile oluşan ve netliği olan mekânları kendi özel alanları olarak belirlemekte ve buralarda daha rahat yaşamaktadırlar. Sixsmith'in yaptığı çalışmada öne çıkardığı 'mutluluk, ait olma ve sorumluluk' ölçütlerine 'özgürlük, tanımlı olma ve ait olma' kavramları da eklenmektedir. Despres ise bu kavramlara ek olarak evin anlamı konusunda 4'lü bir değer dizisi oluşturur ve toplumsal süreçlerin analiz edilerek yapısal forma uyumlarının sağlanması gerektiğini vurgular (Despres, 1991). Somerville ise ev konusuna fenomonolojik ve sosyolojik yaklaşımları birleştirerek yaklaşır. Bu yaklaşımla birlikte evi mahremiyet, kimlik ve aşina olma kavramları ile özdeşleştirir (Somerville, 1997). 2012 yılında 'Journal of housing and the built environment'dergisi konut, ev ve yerleşim (house, home and dwelling) üzerine özel bir sayı çıkartır. Coolen ve Meesters'in yapılan tüm çalışmaları değerlendirdikleri makaleleri şu noktayı kesin vurgular: 'Ev' çok katmanlı, karmaşık ve çok yönlü bir kavramdır (Coolen \& Meesters, 2012). Belirtilen farklı araştırmalardan çıkan sonuçlar ev konusunun teorik çerçevesinin çok çeşitlenebildiğini göstermektedir. Burada önemli olan hangi çerçeveden bakmanın kullanıcı için daha uygun olacağının doğru belirlenmesidir.

Bu makalede değerlendirilen örneklerin ortak paydası farklı coğrafyalarda olmalarına rağmen, kendi sosyal ortamlarını net yansıtabilmeleridir. 
Tartışmanın ilk başında yer alan savaş sonrası İngiltere'de üretilmiş prefabrike evlerin ve Şili'de Aravena'nın tasarladığı sosyal konutların pek çok benzerliği vardır. En önemli ortak özellikleri ise kullanıcı için o an önemli olanı onlara sunabilmiş olmasıdır. Şili'de gelir düzeyi düşük kullanıcılar için bağımsız olmak ve sıcak suya sahip bir evde yaşamak onların şartları için önemliyken, İngiltere'de savaş sonrası yapılan evlerde yaşayanlar için, savaşın izlerini atlatabilecekleri, komşuluk ilişkileri güçlü ve bahçesi olan evler değerlidir. Bu yüzden bu konutları 'ev, yuva' olarak görmüş ve yaşamlarını devam ettirmeyi seçmişlerdir. Gündelik yaşamlarını kurmak bu evlerde mümkün olmuştur. Aslında ekonomik gücün az olmasının burada önemi azalmakta, kullanıcının isteklerinin doğru anlaşılması ise mutlu bir ev için kabul edilebilir bir kıstas oluşturmaktadır.

Birbirinden farklı coğrafyalarda olmalarına rağmen modern mimarlığın tüm izlerini barındıran Pruitt-Igoe ve Robin Hood Gardens'ın kullanıcılara uzun süreli mutlu evler sağlamadığı gerçeğinden hareket edilirse; ters giden, ya da yanlış hesaplanan ne olmuştur? Sorusu sorulabilir. Burada ortak görülebilen en temel eksik yaratılmak istenen komşuluk ilişkilerinin ve bunu sağlaması beklenen ortak alanların eksik olması ya da yanlış tasarlanmasıdır. Yamasaki'in PruittIgoe için tasarladığı sosyal alanlar ekonomik sıkıntılardan dolayı inşa edilememiş; yerini koridorların birbirine bağladığı karanlık katlar almıştır. Robin Hood Gardens'ın gökyüzü sokakları ise çok dardır ve insanların sohbet edebilmesini sağlayamadığı gibi, güvensiz alanlar oluşmasına sebep olarak insanları tedirgin etmiştir.

Insanlar mutlu olmadıkları, kendilerini güvende hissetmedikleri evlerde yaşamak istemezler; çünkü aidiyet duyguları oluşmaz. Gereksinim duydukları temel kıstaslardan biri budur. O nedenle dönemin bu 2 kült yapısı insan yaşamına dokunma konusunda eksik kalmış ve ancak tarihin sayfalarında ya da bir müzenin salonunda hatırlanır olmuşlardır. Oysa Doshi'nin Aranya konutları sosyal yaşamı destekleyen ve bireylerin kendi isteklerini özgürce gerçekleştirebilecekleri tasarımlar olarak oluşmuştur. Çok farklı bir kültürde Vietnam'da Nghia'nın tasarımları da tüm ekonomik hesapların yerli yerinde olmasına, hızlı üretilebilen ve dayanıklı evler olmalarına rağmen henüz 38 adet ile sınırlı kalmıştır. Bunun nedeni, bireylerin önem verdikleri bir kıstas olan yerellik kavramının prefabrikasyon ve çelik malzeme ile tam sağlanamamasıdır.

Bu örnekler arasında farklı bir yere oturan La MéMé ise aslında insanın istediğini özgürce uygulayabildiği bir örnek olarak Şili'deki Villa Verde konutları ile benzerlik göstermektedir. Öğrencilerin, kendi katılımları ile oluşan tasarımdan memnun kaldıkları bilinmektedir. Elbette yıllar içinde, eksik olan pek çok detayın yeniden gözden geçirilmesi gerekmiş ve yenilemeler yapılmıştır. Yapı, politik tartışmaların gündemine oturarak kullanıcının tasarıma katılma sürecinin artı ve eksileri tartışımıştır. Şu an kaderinin ne olacağı bilinmemekle birlikte, bir dönem içinde yaşayan mutlu kesim hep hatırlanacaktır. 
Mimarın sosyal sorumluluğunun nerede başlayıp nerede bittiği sorusunun cevabını vermek kolay değildir. Ancak, kısaca değerlendirilen bu örnekler ışığında şunları söylemek mümkündür: İnsanlar mimarlığın kurallarından önce kendi gündelik yaşamlarının doğru akışını görmek isterler. Temel ihtiyaçlarının giderilmesi, alışkanlıklarının devam edebilmesi, aidiyet ve güven duygularının gelişebilmesi bir konutu 'ev' yapmak için ekonomik güçten daha önemli bir sembolik güç olarak ortaya çıkabilir. Tüm bu temellerin ise sürekliliğinin sağlanması gerekir. Ama mimarlık, dinamik ve devamlı kendini yenilemeye çalışan bir disiplindir. Bunun da ötesinde güzel ve teknolojik olana olan bağımlılığı onu çoğu zaman bir ikileme götürmektedir. 'Güzel' olanı yapmak kadar 'gereken'i yapmak ve yine de kendi prensiplerinden ödün vermemek arasındaki çizgiyi nerede çizeceği konusunun cevabı hiç bir zaman net değildir. Insan yaşamına onun için çok değerli olan 'ev' konusunda dokunmanın tek doğru ve kesin bir çözümü olamayacaktır. Ancak, belki de kabul edilebilecek olan gerçek, konu 'ev' olunca ve dış etkiler güçlü ve zorlayıcı şekilde ortaya çıkınca her zaman mimarın daha iddialı ama bir o kadar da dikkatli ve düşünceli olmaya devam etmesi gereğidir.

Kroll’un dediği ‘insani’ olmanın değeri ve gereği burada yatmaktadır... 


\section{KAYNAKÇA}

Aranya. (n.d.). Erişim yeri http://web.mit.edu/incrementalhousing/articlesPhotographs/pdfs/ aranya-3-Details1146.pdf

Aras, L. (2013). Postmodern tüketim toplumu'nda tasarımcı / kullanıcı perspektifi altında “iyi tasarım" açılımları. Hacettepe Üniversitesi Güzel Sanatlar Fakültesi Sanat Yazıları Dergisi, Sayı 29, 11-24.

Aras, L. (2018). Sosyal konutun itibarı. XXI, Temmuz-Ağustos, 171, 38-39.

Aravena, A. (2013). More than the Enigma of a stone. I like it's calmness. Archldea, Vol. 47, 1015.

Aravena A. (2016). Erişim yeri https://www.nytimes.com/2016/05/23/t-magazine/pritzkervenice-biennale-chile-architect-alejandro-aravena.html

Balkrishna Doshi. (n.d.). Erişim yeri http://www.arkitera.com/haber/29990/priztker-odulunukazanan-balkrishna-doshinin-hayati-ve-projeleri

Ballesteros, M. (2010). Elemental-lessons in pragmatism. Perspecta, Vol. 42, 83-84.

Betts, P. (2003). The politics of post-fascist aesthetics 1950s West and East German industrial design. Life after death approaches to a cultural and social history of Europe during the 1940s and 1950s içinde, Ed. Richard Bessel, Dirk Schumann. New York: Cambridge University Press.

Boano, C. \& Perucich F. V. (2016). Half-happy architecture. Viceversa, Vol. 4, 59-81.

Comerio, M. (1981). Pruitt-Igoe and other stories. JAE, 34 (4), 26-31.

Coolen, H. \& Meesters, J. (2012). Editorial special issue: House, home and dwelling. Journal of Housing and Built Enivironment, 27 (1), 1-10.

Despres, C. (1991). The meaning of home: Literature review and directions for future research and theoretical development. Journal of Architectural Planning and Research, 8 (2), 96115.

Dutton, T. A. \& Mann, L. H. (1995). After modernism: What happened to architecture's social project? 83rd ACSA Annual Meeting, 222-231. 
Erten, C. (2015). Mimarlık pratiklerine kendin-yap (dıy) kültürü üzerinden bir bakış. Yüksek Lisans Tezi. İstanbul: i̇.TÜ.

Fathy. H. (1973). Architecture for the poor; an experiment in rural Egypt. Chicago: University of Chicago Press.

Florian, U. (2013). The hut on the garden plot informal architecture in twentieth-century Berlin. Journal of the Society of Architectural Historians, 72 (2), 221-249.

Huxtable, A.L. (1981). Le Corbusier's housing project-flexible enough to endure. New York Times. Erişim yeri http://www.nytimes. com/1981/03/15/arts/architecture-view-le-corbusier- shousing-project-flexible-enough-endure- ada.html

Jencks, C. (1977). The language of postmodern architecture. New York: Rizzoli.

Le Corbusier. (1986). Towards a new architecture. New York: Dover.

Mallgrave, F. \& Goodman, D. (2011). An introduction to architectural theory, 1968 to the present, UK: Wiley-Blackwell.

Mumford, E. (2000). The CIAM discourse on urbanism, 1928-1960. Cambridge: MIT Press.

Prefabs. (n.d.). Prefabs- the solution to a housing crisis. Erişim yeri http://www.epsomandewellhistoryexplorer.org.uk/MoreOnPrefabs.pdf

Prefabricated housing. (2017). Erişim yeri https://www.nytimes.com/2017/07/05/world/asia/votrong-nghia-prefabricated-housing.html

Rattenbury, K. (2011). 'Too good to be true, the survival of everyday English PoMo'. Architectural Design, 81(5), 106-114.

Robin Hood Gardens. (n.d.). Erişim yeri https://www.archdaily.com/150629/ad-classics-robinhood-gardens-alison-and-peter-smithson

Sebba, R. \& Churchman, A. (1986). The uniqueness of the home. Architecture and Behaviour, 3 (1), 7-24.

S-houses. (n.d.). Erişim yeri https://saigoneer.com/saigon-development/10675-vo-trong-nghiabrings-low-cost-prefabricated-s-houses-to-northern-vietnam

Sixsmith, J. (1986). The meaning of home: An exploratory study of environmental experience. 
Journal of Environmental Psychology, Vol. 6, 281-298.

Somerville, P. (1997). The social construction of home. Journal of Architectural Planning and Research, 14 (3), 226-245.

Spatialagency. (n.d). Erişim yeri http://www.spatialagency.net/database/john.turner

Tanju, B. (2003). Mimarlık ve toplumsal sorumluluk. Arredamento Mimarlık, 100+56, 53-55.

Teerds, H., Habraken, J., \& Havik, K. (2011). Define and let go. An interview with John Habraken. Productive uncertainty. Indeterminacy in Spatial Design, Planning and Management, OASE, (85), 8-16. https://oasejournalnl/en/Issues/85/DefineAndLetGo.

Tester, G. \& Wingfield, A. H. (2013). Moving past picket fences: The meaning of "home" for public housing residents. Sociological Forum, 28 (1), 70-84.

Turner, J. \& Fichter, R. (1973). Freedom to build, dweller control of the housing process. New York: The Macmillan Company.

Turner, C. (2015). Homes through the decades - The making of modern houses. Ingiltere: NHBC Vakfı ve Richards Partington mimarlar grubu.

User participation. (n.d.). Erişim yeri https://www.architectural-review.com/essays/ viewpoints/few-architects-have-embraced-the-idea-of-user-participation-a-newmovement-is-needed/10008549.articleVo

Trong Nghia. (n.d.). Erişim yeri https://www.archdaily.com/780168/ad-interviews-vo-trongnghia-chicago-architecture-biennial

Zhuravlyova, S. (2013). The people's palaces: 70 years on Britain's prefabricated houses are still home to many. Erişim yeri http://www.independent.co.uk/property/gardening/thepeoples-palaces-70-years-on-britains-prefabricated-houses-are-still-home-to-many8646134.html 
Şekiller

1. Prefabs. (n.d.). Erişim yeri English Heritage / Prefabs- the Solution to a Housing Crisis http://www.epsomandewellhistoryexplorer.org.uk/MoreOnPrefabs.pdf

2. Florian, U. (2013). The Hut on the Garden Plot Informal Architecture in Twentieth-Century Berlin, Journal of the Society of Architectural Historians. 72 (2), 221-249.

3. Pruitt- Igoe. (2016). Erişim yeri https://slumsandsuburbs.wordpress.com/2016/04/22/socialhousing-optimism-and-failure-part-1-pruitt-igoe/

4, 5. Lucien Kroll. (n.d.). Erişim yeri https://www.domusweb.it/en/architecture/2010/06/ 30/lucien-kroll-utopia-interrupted.html

6, 7. Poplar. (n.d.). Erişim yeri https://municipaldreams.wordpress.com/tag/poplar/

8, 9. Alejandro Aravena. (2016). Erişim yeri https://www.nytimes.com/2016/05/23/tmagazine/pritzker-venice-biennale-chile-architect-alejandro-aravena.html

10. Asia. (n.d.). Erişim yeri https://www.bbc.com/news/world-asia-india-43326825

11. Archnet. (n.d.). Erişim yeri https://archnet.org/sites/870/media_contents/27770

12, 13. Vo Trong-Nghia. (n.d.). Erişim yeri https://www.archdaily.com/579593/s-house-3-votrong-nghia-architects 


\section{Yazarın Biyografisi:}

* Prof. Dr. Lerzan Aras

1988 yılında I.T.Ü Mimarlık Fakültesi'nden mezun oldu. Tarihi çevre koruma üzerine yüksek lisans çalışmalarını tamamladıktan sonra, işletme yüksek lisans çalışmalarını ve mimarlıkta eleştiri üzerine doktorasını aynı anda yürüttü. Araştırma görevlisi olarak da çalıştığı iTü'deki akademik hayatını doktora bitimininde sonlandırdı ve farklı çalışma alanları ile farklı üniversitelerde deneyimler edindi. Şu an Lefke Avrupa Üniversitesi Mimarlık Fakültesi'nde öğretim üyesi olarak görev yapmakta; yaşam, ev, gündelik hayat, sosyoloji ve mimarlık, travma geçirmiş mekanlar, sosyal sorumluluk ve tüm bu kavramların insan ile ilişkisi üzerine çalışmalarına devam etmektedir. 